\title{
What Factors Affect Nursing Students' Decisions of Whether to Take Rural Jobs: An Exploratory Interview Study in China
}

\author{
Yuexian Tao ${ }^{1}$, Elaine Haycock-Stuart ${ }^{2} \&$ Sheila E. Rodgers ${ }^{2}$ \\ ${ }^{1}$ School of Nursing, Hangzhou Normal University, Zhejiang, China \\ ${ }^{2}$ School of Health, University of Edinburgh, Edinburgh, UK \\ Correspondence: Yuexian Tao, School of Nursing, Hangzhou Normal University, No.16 Xuelin Street, Hangzhou, \\ 310036, China. Tel: 86-571-2886-5393. E-mail: taoyuexian@126.com
}

Received: August 26, 2016

Accepted: September 24, 2016

Online Published: October 20, 2016

doi:10.5430/ijhe.v5n4p165

URL: http://dx.doi.org/10.5430/ijhe.v5n4p165

\begin{abstract}
Purpose: The purpose of this study was to explore factors that affact nursing students' decisions of whether to take rural jobs in China. Methods: An exploratory interview study was conducted in China during May and June 2011. Eleven final year nursing students were purposively recruited from four nursing schools in one eastern area in China. The semi-structured interviews were audiotaped, transcribed and then analysed using thematic analysis approach. Findings: Four major themes emerged from these interview data: (a) students' perspectives on rural nursing posts; (b) student's perspectives on rural communities; (c) students' background and personal concerns; and (d) government recruitment policies of rural nurses. Participants viewed rural nursing posts as positions with lower financial rewards, lower social status and fewer opportunities for professional development. They also perceived rural nursing as less demanding and less stressful. Rural background and altruistic personality contribute to students' intentions to take a rural job. Family members' disapproval of rural jobs was a major barrier to nursing students taking a rural job. Conclusions: The perceived low social status of rural nurses and family members' disproval of rural work were unique factors revealed in Chinese context that had negative impacts on students' intentions to work in rural places.
\end{abstract}

Keywords: Nursing students, Career intentions, Workforce, Rural areas

\section{Introduction}

\subsection{Introduce the Problem}

China has a large proportion of rural populations. In 2014, there were still $46.3 \%$ of its population living in rural areas. However, the nursing workforce in rural areas and urban areas was distributed unevenly, with greater numbers and more highly qualified nurses working in urban areas while fewer and less educated nurses working in rural places (Ministry of Health of PRC, 2014).

Currently, the workforce in rural areas in China is mainly based on graduate recruitment. Under previous planned economy, some graduates from tertiary education and secondary technical schools were mandatorily distributed to rural areas by government. In the current market orientated economy, the employment policies were reformed to a free job settlement stage (The Central People's Government of PRC, 1993), which means graduates can choose workplaces by themselves. However, little is known about how new nurse graduates consider the work opportunities of rural nursing posts under the marketing system and how different levels of education impact on their decisions.

Nursing education programmes in China are classified into Zhongzhuan, Zhuanke, Benke and Yanjiusheng in Chinese, which equivalent to diploma, associate, baccalaureate and graduate programs in the United States. The diploma program is categorized by the government as secondary vocational education. Currently, it admits students from junior high schools and has a three-year curriculum. The associate nursing program is postsecondary nursing education and it lasts two or three years. The bachelor program admits high school graduates through the national university admission examination and has 4-5 years curriculum. The master program in nursing usually lasts three years in length and enrols students who have a bachelor degree.

\subsection{Literature Review}

Previous research studies have revealed some factors influencing rural nursing recruitment, such as professional development, financial rewards, working environment and community environment. In the literature, a lack of 
professional support, poor equipment and inadequate supplies were identified as major challenges in rural nursing practice (Bushy \& Leipert, 2005; Francis, Bowman, \& Redgrave, 2001; Mullei et al., 2010). Lack of anonymity was considered to have negative impact on rural recruitment (Bourke et al., 2004). Salary for nurses in rural areas was usually reported to be lower than for their urban counterparts. For example, in the USA, Skillman et al. reported that the more rural the registered nurses lived, the lower salary they received according to the data from a national sample survey in 2000 (Skillman, Palazzo, Keepnews, \& Hart, 2006).

However, not all the factors reported were negative; there were some attractions for graduates to take a rural job. More personal autonomy in their work was thought to be one of the unique characteristics of rural practice and could encourage graduates to take a rural job (Bourke et al., 2004; Mullei et al., 2010). Studies also reported some rural community environment factors influenced nurses or nurse students' decisions to work rurally, such as people's friendliness, the relaxed rural lifestyle (Manahan, Hardy, \& MacLeod, 2009), and a natural environment to raise children (Bushy \& Leipert, 2005).

Some studies reported that diversity of skills used in rural facilities attracted some health professionals to rural practice and encouraged undergraduate students to consider remote and rural practice (Manahan et al., 2009; McAuliffe \& Barnett, 2009). However, in contrast, it was also reported that the characteristic of mixed skills used in rural health services discourages some graduates from seeking rural employment, although it might be a reason for them to select a rural health facility as a clinical placement place to obtain a wide variety of clinical experience (Lea et al., 2008).

Most of the above mentioned factors were reported by researchers undertaking studies in countries without the Chinese context. The findings from the literature may not reflect the situation in China. In order to identify what influences Chinese nursing students' decisions of whether to work in rural places, the exploratory interview study was designed and carried out.

\section{Method}

\subsection{Sampling Procedures}

The sample of this exploratory study was a purposive sample. Participants were recruited based on the following criteria. The first was being a final-year nursing students, secondly education level and thirdly residence background. Students were recruited from the diploma program, associate program or bachelor program. Access to the participants strictly followed a strict protocol of initially making contact with the deans or the chief teachers at nursing schools by telephone or email.After obtaining permission, the deans were asked to advertise or e-mail the research information to the final-year nursing students who were then recruited from those who agreed to be interviewed This recruitment process ensured that the students interviewed and the schools where they were studying were well informed and agreeable to taking part in the study.

\subsection{Participant Characteristics}

The recruitment of participants commenced in May 2011, and ended in late June 2011. In total, there were eleven interviewees, including five diploma students, four bachelor students and two associate students. As the recruitment and the conduct of interviews were iterative, they lasted for nearly two months. All the interviewees were female and ranged from 18-24 years old. The attributes of all participants involved in this exploratory interview study are summarised in Figure 1. 


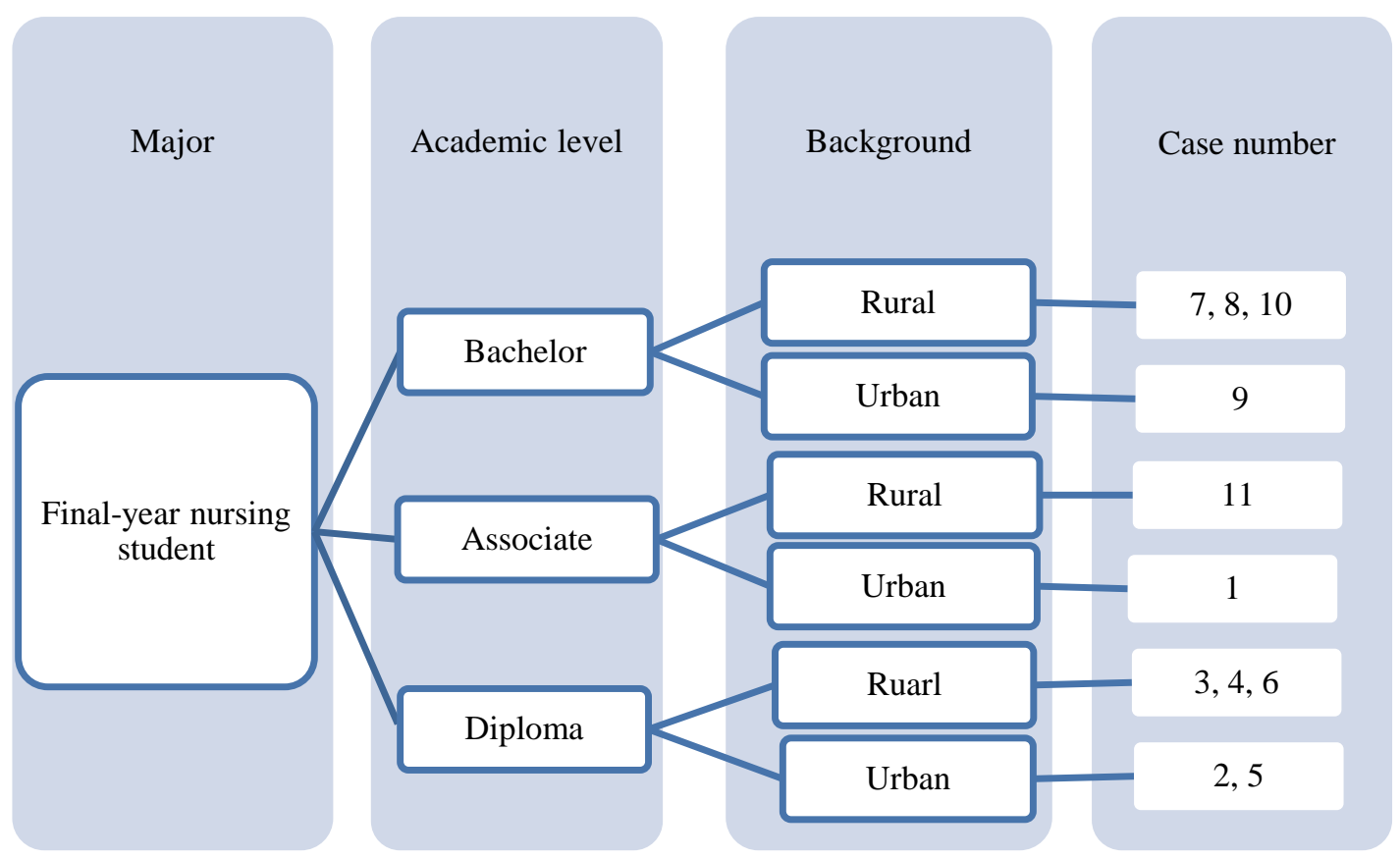

Figure 1. The Participants and Their Attributes

\subsection{Data Collection}

All interviews were conducted face-to-face by the first author during May and June 2011. Given that the first language of all participants was Mandarin, the interviews were conducted in Mandarin. A mini-digital recorder was used to record these interviews.

\subsection{Ethical Considerations}

The study was given ethical approval by a committee in the University in the UK and by a panel of nursing education experts in China.

An information sheet, containing the credentials of the researchers, the purpose and procedures of the study, potential cost and benefits of the interviews, was sent to potential participants via staff in the nursing schools. Nursing students were also informed that participation was voluntary and that they could withdraw at any stage. During the interview, a written consent form was signed by both the participant and the researcher. No participant could be identified from the recordings or transcriptions. All data were stored securely and computers were password protected.

\subsection{Data Analysis}

The recordings were transcribed to paper verbatim in Chinese. When writing in English, excerpts quoted in the paper were translated from Chinese and were checked for accuracy by a native English speaker and a Chinese PhD student who studied in the UK. Thematic analysis was employed to analyse the data. NVivo 9.0 was used to manage the data and facilitate the data analysis.

\section{Results}

The exploratory interviews revealed that there were a great number of factors that influence nursing students' decisions of whether to work in rural places. Four major themes emerged from the data analysis. These themes were (a) students' perspectives on rural nursing posts; (b) students' perspectives on rural communities; (c) student's background and personal concerns; and (d) rural recruitment policies. These major themes and their subthemes were shown in Figure 2. 


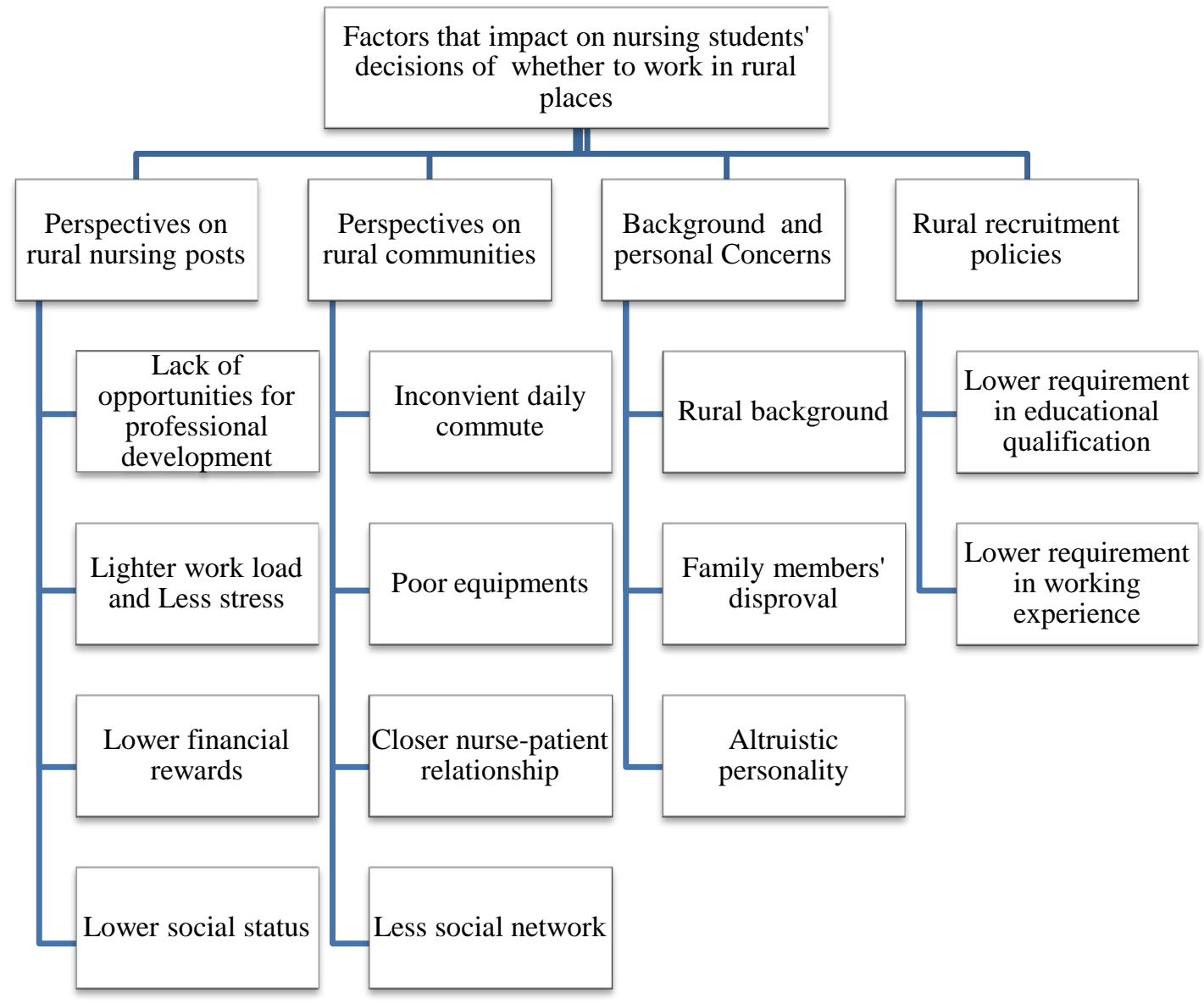

Figure 2. Diagram of Factors That Impact on Nursing Students' Decisions of Whether to Work in Rural Places

\subsection{Students' Perspectives on Rural Nursing Posts}

The interviews revealed that most of the participants viewed rural nursing posts as positions with a light workload and less stress with fewer opportunities for professional development, lower financial rewards and lower social status compared with those urban nursing posts.

\subsubsection{Fewer Opportunities for Professional Development}

Most of the interviewees thought the health facilities in rural areas could not provide them with many opportunities to experience diverse skills, as the size of the hospital was generally small in most rural areas and most of the patients were not as severely ill as those in some city hospitals, and the equipment in rural health facilities usually was not advanced enough. The phrase 'I can learn more in a city hospital' was used frequently by the interviewees when they described the reasons why they chose not to work rurally.

“... I think for a new graduate, a youth, directly working in a rural hospital, which is usually small in scale, is not good. I think that would limit my own career development. Thus I need to go to a big hospital and get my experience there." (Excerpt from participant 10)

"By working in cities, maybe you can develop yourself well... Lots of patients go to city hospitals, because the techniques there are better than in rural hospitals, and thus lots of graduates choose to work in the cities." (Excerpt from participant 4)

\subsubsection{Lower Financial Rewards}

In terms of the financial rewards, there was a popular view among the interviewees that financial rewards in rural areas were lower than in cities. Students mentioned that financial rewards like salary, bonuses and insurance premiums paid by employers would be better in city hospitals than in rural health facilities. Some students described that this was one of the main reasons for them not to consider a rural job. 
"To be honest, the main reason is the financial rewards. The financial rewards in big hospitals are better than in other health facilities...for example, bonuses, bonuses are based on the number of patients a hospital treats." (Excerpt from participant 11)

\subsubsection{Lower Social Status}

Along with lower financial rewards, students also considered that the social status for rural nurses was not as high as urban nurses. In the interviews, more than two thirds of the students mentioned the social status of rural nurses. They used the words and phrases, like 'prestige', 'proud', 'social status' and 'reputation' to describe their feelings. Out of eleven interviewees, nine of them thought that working in the city was more honorable than working in rural areas.

“... The negative aspect is that it [working in a rural health facility] is not honorable. If you are working in a big hospital, you can be very proud when you tell others where you work." (Excerpt from participant 3)

\subsubsection{Light Workload and Less Stress}

When students complained about the fewer opportunities for professional development, lower financial rewards and lower social status of rural nurses, they would, however, appreciate the relatively light workload and less stressful working environment in rural health facilities. They perceived the work in rural health facilities was easier in contrast to it being perceived to be more demanding in some city hospitals.

"As there are less patients in rural hospitals, working there is not so busy. If you are working in a big hospital you have to hurry up around the wards the whole day, with no free time. " (Excerpt from participant 5)

\subsection{Students'Perspectives on Rural Community}

Along with the above views related to nursing posts, there were many concerns in terms of rural communities. Students perceived rural communities to have limited and inconvenient transportation, poor opportunities for social networking, poor health care facilities but with opportunities for close nurse-patient relationships.

\subsubsection{Inconvenient in Daily Commute}

With regards to a rural job, some students thought that the daily commute in rural areas was not convenient, especially for those students from an urban residence.

"My family is living in a city, so it is not convenient forth and back every day. And I don't know the people there, so it is not meaningful for me to work there. It is too far." (Excerpt from participant 1)

\subsubsection{Poor Opportunities for Social Networks}

The social network was mentioned by some interviewees. They thought the social network they could build in rural areas might not be as wide as the one they could have in a city.

"You can meet lots of people in the city, so you can have a wide social network and social knowledge." (Excerpt from participant 11)

"I think that if you stay in rural areas, you will fall behind other graduates in terms of the social network you build." (Excerpt from participant 2)

\subsubsection{Poor Facilities in Rural Health Institutions}

Some interviewees mentioned that the equipment in rural health facilities was poor. If there is a limited opportunity for using technical equipment, their potential for developing skills and their ability may not be fully developed.

".......But as for the equipment there [in rural places], healthcare providers who mastered advanced skills would not be willing to work there...Because of the poor equipment...they may feel their skills are useless; there is no equipment for them to use." (Excerpt from participant 9)

\subsubsection{Close Nurse-patient Relationship}

The nurse-patient relationship was mentioned by several interviewees. They perceived the nurse-patient relationship in rural areas as less strained than that in urban areas and this perspective could facilitate nursing students to take a rural job.

"In big hospitals, interpersonal relationships, especially the nurse-patient relationships, are strained...... However, in a rural health facility patients can be treated as relatives and they talk with each other softly. From this reason, I like to work rurally."(Excerpt from participant 9) 


\subsection{Students' Background and Personal Concerns}

Excerpt for students' perspectives in rural nursing posts and rural communities, there were factors from students' background and personal issues. Students' rural background, altruistic personalities and their family member's disapproval of a rural job were mostly mensioned in the interviews.

\subsubsection{Rural Background}

Analyzing the interview data, it was found that there were not many students willing to work rurally, but among those willing to do so, having a rural background played an important role in their decisions. Some interviewees with rural backgrounds expressed that they might work in rural areas in their later career.

"I like working in a rural nursing station ... As I was born in a rural area ... I do not want to leave there." (Excerpt from participant 3, 19 years old)

"... after I having worked in a city for a few years, I may consider working rurally, but at the moment of graduation, I think I need to go to a big hospital to further develop myself" (Excerpt from participant 7, 24 years old)

At the same time, one interviewee from an urban background emphasized that there was little possibility for her to work rurally during her career.

"Er... there is little possibility for that [work in a rural area] — unless there are tremendous incentives. (Excerpt from participant 9, 23 years old)

\subsubsection{Altruistic Personality}

The interviews revealed that students had different personal values in terms of what they expected from their job, and altruistic personality played an important role in considering a rural job.

"Er... I would like to work in rural areas. By doing this, I can help the poor people there. For them, because of the lack of money, it is difficult to go to big hospitals to receive treatment and the rural health facilities are the only choice for them. I like to work there." (Excerpt from participant 3, 19 years old)

\subsubsection{Family Members' Disapproval}

The exploratory interviews revealed that family members usually participated in students' decisions of workplace selection. Sometimes, parents' opinions seemed to be the decisive force, and some students even relied on their parents' opinions and arrangements.

“...My parents' opinion is more crucial. They asked me to attend that examination [recruitment examination]." (Excerpt from participant 8, 24 years old)

\subsection{Recruitment Policies}

This final theme revealed that there were some existing policies that encourage nursing students to take rural jobs. Lower requirement in educational qualification give opportunities for those diploma or associate graduates to take formal jobs in rural places, and the policy that no working experience was required allowed the new graduates to have opportunities to work community centres in rural places.

\subsubsection{Lower Requirement in Educational Qualification}

In the interviews, students mentioned that in the market-oriented system it was easy for bachelor program graduates to find a job in city hospitals, whereas for diploma students it was difficult. While, in rural health facilities in China, the requirement for educational qualification was relatively lower than in a city hospital. This encouraged diploma students to seek jobs in rural areas.

"As for a diploma qualification graduate, the only possibility is to go to rural areas. Now some county hospitals do not accept diploma graduates, and next year even associated graduates may not be accepted, they ask a bachelor degree or above."(Excerpt from participant 2)

"For some comprehensive hospitals, like the one I will enter, only bachelor graduates can get a formal position, and an associate graduate can only work as a contract nurse." (Excerpt from participant 9).

\subsubsection{Lower Requirement of Working Experience}

In the interviews, students mentioned that to obtain a position in a community health centre in a city, two years of working experience was usually required, but no working experience was required to be employed in rural 
community centres in some counties, which means nursing graduates were allowed to enter the rural community centres right after their graduation.

"There is a new policy for graduates to work in rural areas. It is to support the rural health institutions. Usually two years working experience are required for entering a community healthcare centre in cities, but in rural health facilities, new graduates without working experience are allowed to work there." (Excerpt from participant 9)

\section{Discussion}

In this exploratory study, four themes emerged as major factors influencing nursing students' intentions to work in rural places. The first theme revealed that students considered the opportunity of continuing professional development when they selected their workplaces. This was in congruence with the report that new graduates had an expectation that their employers would provide a supportive learning environment for them to gain the skills necessary to become proficient and valuable employees (Bennett, Barlow, Brown, \& Jones, 2012). The findings indicate that facilities in rural places should provide more learning and training opportunities to attract new graduates. The data also revealed that student nurses had a perception that the social status of rural nurses was lower than their expectation and this is a major barrier for them to consider a rural setting position. This was not reported in other literature. This unique phenomenon may link to Chinese context, as Chinese students are quite concerned with the feelings of their family members and the issue of keeping 'face' (Martin de, 2012). The first theme also revealed that nursing students viewed rural nursing positions as less demanding and less stressful. This perspective is in contrast to previous reports from other countries which identify rural nursing work as having a higher workload and having more night duties than their city counterparts (Mullei et al., 2010). This contrasting view may result from the unique rural health delivery system in China which seldom imposes on call or out of hours' services on rural nurses.

The second theme revealed that nursing students worried about social networking opportunities, the quality of equipment in rural health facilities, and the transportation system in rural communities when they considered whether to take a rural job. However, the potential for nurse-patients relationships were viewed favorably. These finding are in many ways in accordance with reports from previous literature (Bushy \& Leipert, 2005; Lea \& Cruickshank, 2005; Mullei et al., 2010). The fact that a lack of social network in rural areas emerged as a negative factor for nursing students to take a rural job indicates that social networking has become an important part of the life of Chinese younger generations.

Through the third theme, students' rural experience, family member's support and students' altruistic personalilty could contribute to the intentions to work rurally. The finding about rural experience added more evidence to the conclusion that rural background had a robust impact on rural health professional recruitment (Blaauw et al., 2010; Saini, Sharma, Roy, \& Verma, 2012; Schofield, Fletcher, Fuller, Birden, \& Page, 2009). This suggests that recruitment strategies that target rural background graduates would be a useful strategy to increase the uptake of rural nursing jobs. Family member's disapproval of rural work is a unique phenomenon in Chinese context and it reflected that rural nursing posts were not perceived as ideal posts by some nursing students' parents. This phenomenon reflected a strong family-tie culture in China and the importance of work status to families. This study also revealed that altruistic motivation played an important role in some students' decision to work in rural places. This suggests that fostering the faith to help others is still a necessary way to increase the younger nurse generation in rural health facilaties in the market oriented economy system.

The fourth theme is related to recruitment policies. Lower requirements were set in response to the situation that few highly qualified nursing students had intentions to work rurally. However, whilst these policies allowed lower educationally prepared graduates to work rurally, they might have discouraged more highly qualified nursing graduates to work rurally. Thus, these policies are not likely to benefit the improvement of the rural workforce in a longer term. We believe developing some recruitment policies to attract more highly qualified nursing students to rural practice is important for better health care in China. For example, a flexible policy that allows nurses to flow freely between rural and urban health institutions would be effective to enable those more highly qualified candidates to work in rural places for a period of time.

\section{Limitations and Implications}

This study has some limitations. As a limited sample was drawn, the results of this study were not generalizable. The findings might not sufficiently reflect all nursing students' opinions, but there was an opportunity for transferability of findings to wider contexts. In addition, although these interviews revealed a set of factors related to nursing students' decisions to work in rural places, they provided limited evidence regarding the relative importance of these factors. To investigate the relative importance of these factors, further research was needed.

There were many factors that affected nursing students' decisions of whether to take a rural job. The perceived low 
social status of rural nurses and family member's disproval of rural work were unique factors specifically pertinent to the context in China as they have not been reported in previous studies from other countries. We believe policies, such as raising the social status of rural nurses, increasing mobility to allow nurses to change workplaces more easily between rural and urban areas, should be developed to encourage more highly qualified nursing students to work rurally and ensure good standards of healthcare.

\section{Acknowledgements}

We would like to thank all of the interviewees who participated in the study and all nursing schools that permitted access for this study.

\section{References}

Bennett, P., Barlow, V., Brown, J., \& Jones, D. (2012). What do graduate registered nurses want from jobs in rural/remote Australian communities? Journal of Nursing Management, 20(4), 485-490. http://dx.doi.org/10.1111/j.1365-2834.2011.01254.x

Blaauw, D., Erasmus, E., Pagaiya, N., Tangcharoensathein, V., Mullei, K., Mudhune, S., et al. (2010). Policy interventions that attract nurses to rural areas: a multicountry discrete choice experiment. Bulletin Of The World Health Organization, 88(5), 350-356. http://dx.doi.org/10.2471/BLT.09.072918

Bourke, L., Sheridan, C., Russell, U., Jones, G., DeWitt, D., \& Liaw, S. (2004). Developing a conceptual understanding of rural health practice. Australian Journal of Rural Health, 12(5), 181-186. http://dx.doi.org/10.1111/j.1440-1854.2004.00601.x

Bushy, A., \& Leipert, B. D. (2005). Factors that influence students in choosing rural nursing practice: a pilot study. Rural And Remote Health, 5(2), 387-387. http://www.rrh.org.au/articles/subviewnew.asp?Article ID=387.

Francis, K., Bowman, S., \& Redgrave, M. (2001). Rural Nurses: Knowledge and Skills Required by to Meet the Challenges of a Changing Work Environment in the 21st Century: A Review of the Literature. Commonwealth Department of Education,Science and Training. http://www.voced.edu.au/docs/dest/TD_TNC_71_176.pdf.

Lea, J., \& Cruickshank, M. (2005). Factors that influence the recruitment and retention of graduate nurses in rural health care facilities. Collegian, 12(2), 22-27. http://dx.doi.org/10.1016/S1322-7696(08)60489 -8

Lea, J., Cruickshank, M., Paliadelis, P., Parmenter, G., Sanderson, H., \& Thornberry, P. (2008). The lure of the bush: do rural placements influence student nurses to seek employment in rural settings? Collegian, 15(2), 77-82. http://dx.doi.org/10.1016/j.colegn.2008.02.004

Manahan, C. M., Hardy, C. L., \& MacLeod, M. L. P. (2009). Personal characteristics and experiences of long-term allied health professionals in rural and northern British Columbia. Rural And Remote Health, 9(4), 1238-1238. http://www.rrh.org.au/articles/subviewnew.asp?ArticleID=1238

Martin de, J. (2012). The pros and cons of Confucian values in transport infrastructure development in China. Policy and Society, 31, 13-24. http://dx.doi.org/10.1016/j.polsoc.2012.01.005

McAuliffe, T., \& Barnett, F. (2009). Factors influencing occupational therapy students' perceptions of rural and remote practice. Rural And Remote Health, 9(1), 1078-1078. http://www.rrh.org.au/publishedarticles/ article_print_1078.pdf

Ministry of Health of PRC.(2009). China's health statistics yearbook 2009: Beijing: Ministry of Health, PRC. http://www.moh.gov.cn/htmlfiles/zwgkzt/ptjnj/year2010/index2010.html.

Mullei, K., Mudhune, S., Wafula, J., Masamo, E., English, M., Goodman, C., et al. (2010). Attracting and retaining health workers in rural areas: investigating nurses' views on rural posts and policy interventions. BMC Health Services Research, 10 Suppl 1, S1-S1. http://dx.doi.org/10.1186/1472-6963-10-S1-S1

Saini, N. K., Sharma, R., Roy, R., \& Verma, R. (2012). What impedes working in rural areas? A study of aspiring doctors in the National Capital Region, India. Rural And Remote Health, 12, 1967-1967. PMID: 22424101

Schofield, D., Fletcher, S., Fuller, J., Birden, H., \& Page, S. (2009). Where do students in the health professions want to work? Human Resources For Health, 7(1), 74-74. http://dx.doi.org/10.1186/1478-4491-7-74

Skillman, S. M., Palazzo, L., Keepnews, D., \& Hart, L. G. (2006). Characteristics of Registered Nurses in Rural versus Urban Areas: Implications for Strategies to Alleviate Nursing Shortages in the United States. Journal of Rural Health, 22(2), 151-157. http://dx.doi.org/10.1111/j.1748-0361.2006.00024.x

The Central People's Government of PRC (1993). Guidelines for China education reform and development. Beijing: the Central People's Government of the People's Republic of China. Retrieved 12th April 2013, from http://www.gmw.cn/content/2010-07/16/content1182748.htm 